\title{
The Implementation of Blended Learning Model via Whatsapp for Improving Understanding Skill Units of Length for The Second Grade Students of Elementary School
}

\section{Slamet Tri Widodo}

Universitas Sebelas Maret

widodo24497@gmail.com

\section{Article History}

received 30/4/2021

\begin{abstract}
Nowadays, distance learning in pandemic covid-19 needs learning model can fit with the situation. It must be important to do because the students can have the understanding skill especially the students are in the second grade. This study aims to improve understanding skill units of length by applying blended learning model via whatsapp and to describe the result of implementing blended learning model via whatsapp in improving understanding skill units of length for the second grade students of SDN 2 Kendalsari Klaten in The Academic Year of 2020/2021. This research is a Classroom Action Research (CAR). The subjects of this research is amount 15 students. This research results blended learning model via whatsapp can improve the understanding skill units of length for the second grade students. It has been showed that the students pass the test as many as 13 from 15 students (86,67\%). The conclusion of this research is implementation of blended learning model via whatsapp is able to improve understanding skill units of length for the second grade students of SDN 2 Kendalsari Klaten in the academic year of 2020/2021.
\end{abstract}

Keywords: blended learning model, whatsapp, units of length, understanding skill

\section{Abstrak}

Pembelajaran jarak jaruh pada masa pandemi covid-19 membutuhkan model pembelajaran yang sesuai dengan kondisi saat ini. Hal itu penting untuk dilakukan agar pemahaman konsep peserta didik dapat meningkat. Tujuan penelitian adalah untuk meningkatkan pemahaman konsep satuan panjang melalui penerapan model blended learning melalui whatsapp pada peserta didik kelas II SDN 2 Kendalsari Klaten dan untuk mendeskripsikan hasil penerapan model pembelajaran blended learning melalui whatsapp dalam meningkatkan pemahaman konsep peserta didik kelas II SDN 2 Kendalsari Klaten. Penelitian tindakan kelas (PTK) dilaksanakan dalam tiga siklus. Subjek penelitian berjumlah 15 peserta didik. Hasil penelitian menunjukkan model blended learning melalui whatsapp dapat meningkatkan pemahaman konsep satuan panjang peserta didik. Hal tersebut ditunjukkan dengan ketuntasan klasikal pada siklus III sebesar $86,67 \%$ (13 dari 15 peserta didik). Kesimpulan penelitian adalah penerapan model blended learning melalui whatsapp dilaksanakan sesuai sintaks dapat meningkatkan pemahaman konsep satuan panjang peserta didik kelas II SDN 2 Kendalsari Klaten Tahun Pelajaran 2020/2021.

Kata kunci: model blended learning, whatsapp, satuan panjang, pemahaman konsep 


\section{PENDAHULUAN}

Guru yang profesional pada zaman sekarang ini wajib diwujudkan. Salah satu kemampuan yang harus dimiliki oleh guru adalah kompetensi pedagogik. Kompetensi pedagogik diantaranya adalah mampu memanfaatkan teknologi informasi dan komunikasi untuk kepentingan pembelajaran dan menyelenggarakan pembelajaran yang baik. Sehingga kemampuan guru dalam melaksanakan pembelajaran dan mengintegrasikan teknologi informasi dan komunikasi sangat dibutuhkan dalam era digital seperti sekarang. Pembelajaran menggunakan literasi digital bisa diterapkan melalui penerapan model pembelajaran blended learning tipe flipped classroom.

Blended learning menurut Husamah (2014) adalah suatu model pembelajaran yang menggbaungkan ciri-ciri terbaik dari pembelajaran tatap muka dan ciri-ciri terbaik dari pembelajaran online untuk meningkatkan pembelajaran mandiri secara aktif oleh peserta didik dan mengurangi jumlah waktu tatap muka di kelas. Implementasi model pembelajaran blended learning dapat menggunakan aplikasi Whatsapp. Whatsapp merupakan salah satu platform online yang membantu guru dalam mengorganisasikan segala tugas-tugas yang dikirmkan oleh peserta didik. Tugas yang dikirimkan guru di platform Whatsapp akan dijelaskan lagi ketika pembelajaran tatap muka sehingga kemampuan pemahaman konsep peserta didik meningkat. Adapun indikator yang menunjukkan pemahaman konsep menurut Hidayat (2018), antara lain: (1) menyatakan ulang sebuah konsep; (2) mengklasifikasi obyek-obyek menurut sifat-sifat tertentu; (3) memberi contoh dari konsep; (4) menyajikan konsep dalam berbagai bentuk representasi matematis; dan (5) mengembangkan syarat perlu atau syarat cukup suatu konsep.

Kemampuan pemahaman konsep harus lebih berhati-hati karena jika peserta didik salah konsep, materi yang disampaikan akan tidak bermakna bagi peserta didik. Salah satu konsep yang harus dikuasai peserta didik adalah satuan panjang. Sayangnya keadaan tersebut berbanding terbalik dengan data yang diperoleh peneliti dari hasil observasi dengan guru kelas II SDN 2 Kendalsari Klaten. Observasi kinerja guru sebelum tindakan yang dilakukan peneliti menghasilkan bahwa selama pembelajaran daring masa pandemi covid-19 guru hanya memberikan tugas tanpa adanya tindak lanjut dan kurangnya inovasi dalam memberikan sumber belajar kepada peserta didik. Data lain yang menguatkan adalah data wawancara yang didapat peneliti. Hasil wawancara bersama guru menunjukkan bahwa guru sering menggunakan metode ceramah, pembelajaran belum menerapkan literasi digital dan teknologi, dan penerapan model pembelajaran belum maksimal. Data tes pratindakan yang dilaksanakan oleh peneliti juga menunjukkan bahwa peserta didik yang memperoleh nilai di bawah KKM $\geq 78$ dengan presentase ketuntasan sebesar $11 \%$ atau 3 dari 15 peserta didik yang mencapai KKM. Hal ini membuktikan bahwa rendahnya kemampuan pemahaman konsep satuan panjang pada peserta didik kelas II SDN 2 Kendalsari Klaten Tahun Pelajaran 2020/2021.

Kurangnya kemampuan pemahaman konsep satuan panjang maka diperlukan suatu perbaikan dalam pelaksanaan pembelajaran. Penelitian yang dilakukan oleh Roshonah et al. (2020) membuktikan bahwa penerapan model blended learning dapat meningkatkan prestasi belajar matematika sekolah dasar. Penelitian lain melalui penerapan model pembelajaran berbasis blended learning melalui media whatsapp dapat meningkatkan critical thinking pada siswa SD merupakan penelitian dari Masitoh, Yuliyanti, \& Lestari (2018). Penelitian Rizkiyah (2018) menunjukkan peningkatan hasil belajar siswa pada mata pelajaran ilmu bangunan pada siswa SMK. Meskipun ada perbedaan subjek penelitian tapi hal tersebut membuktikan bahwa penerapan model blended learning dapat memperbaiki pelaksanaan pembelajaran. Berdasarkan beberapa penelitian tersebut, perbaikan kemampuan pemahaman konsep satuan panjang pada muatan pembelajaran Matematika sangat diperlukan melalui penerapan model pembelajaran blended learning tipe flipped classroom 
menggunakan platform Whatsapp. Hal ini sesuai dengan keadaan sekarang yang masih masa pandemi covid-19 sehingga pembelajaran dilaksanakan dominan di rumah. Oleh sebab itu, penerapan model blended learning tipe flipped classroom melalui whatsapp cocok pada permasalahan yang telah dijelaskan. Menurut Rooney (2003) blended learning merupakan model pembelajaran yang menggabungkan antara sistem e-Learning dengan metode konvensional atau tatap muka (face-to-face). Sedangkan model flipped classroom menurut Doherti \& Wulandari (2020) adalah model pembelajaran yang dapat merangsang peserta didik untuk aktif dalam proses belajar dan menuntut peserta didik lebih mandiri karena peserta didik dituntut untuk selalu belajar di luar kelas sebelum mengikuti proses belajar mengajar di kelas. Dalam menerapkan model blended learning tipe flipped classroom dibutuhkan sebuah platform online yang mudah dan menarik bagi peserta didik. Whatsapp merupakan salah satu media sosial yang saat ini banyak digunakan karena kemudahannya dalam mengakses informasi. Menurut Masitoh, Yuliyanti, \& Lestari (2018) aplikasi whatsapp merupakan aplikasi pesan dengan kelebihan dapat digunakan dalam kegiatan forum, grup, atau kelas.

Model blended learning tipe flipped classroom melalui whatsapp menurut Wicaksono (2015) memiliki sintaks seperti berikut ini: (1) Fase 0 (Peserta didik belajar mandiri sebelum melaksanakan pembelajaran di kelas); (2) Fase 1 (Datang ke kelas untuk melakukan kegiatan belajar mengajar dan mengerjakan tugas yang berkaitan dengan materi yang akan dipelajari); (3) Fase 2 (Menerapkan kemampuan peserta didik dalam proyek dan simulasi lain di dalam kelas); dan (4) Fase 3 (Mengukur pemahaman peserta didik yang dilakukan di kelas pada akhir materi pelajaran).

Berdasarkan uraian tersebut, maka tujuan dari penelitian ini adalah menerapkan model pembelajaran blended learning melalui whatsapp untuk meningkatkan pemahaman konsep satuan panjang pada peserta didik kelas II dan mendeskripsikan penerapan model blended learning melalui whatsapp dalam meningkatkan pemahaman konsep satuan panjang pada peserta didik kelas II. Manfaat penerapan model blended learning melalui whatsapp dalam pembelajaran adalah menambah wawasan bagi guru dalam pembelajaran jarak jauh mengenai penerapan model blended learning melalui whatsapp dan pemahaman konsep satuan panjang peserta didik meningkat.

\section{METODE}

Penelitian ini telah dilaksanakan di SD Negeri 2 Kendalsari Klaten Tahun Pelajaran 2020/2021 pada bulan Januari 2021 sampai bulan Mei 2021. Penelitian tindakan kelas (PTK) menurut Hermawan (2015) merupakan proses untuk memperbaiki dan meningkatkan kualitas pembelajaran yang dilaksanakan guru sendiri demi tercapainya prestasi yang meningkat. Penelitian ini dilaksanakan dalam tiga siklus dengan setiap siklus terdiri dari dua pertemuan. Tahapan-tahapan dalam penelitian tindakan kelas menurut Arikunto et al. (2017), yaitu: (1) perencanaan; (2) pelaksanaan; (3) pengamatan; dan (4) refleksi. Subjek penelitian adalah peserta didik kelas II SD Negeri 2 Kendalsari Klaten Tahun Pelajaran 2020/2021.

Sumber data dari penelitian ini adalah guru, siswa, observer, dan dokumen. Teknik pengumpulan data menggunakan teknik tes, lembar observasi, pedoman wawancara, dan dokumentasi. Uji validitas data dalam penelitian ini menggunakan teknik triangulasi meliputi triangulasi sumber dan triangulasi teknik.

Teknik analisis data menggunakan model interaktif oleh Miles Huberman. Indikator kinerja yang diharapkan dalam penelitian ini adalah sebesar $80 \%$ dengan KKM $\geq 78$ untuk ketuntasan hasil belajar peserta didik tentang pemahaman konsep satuan panjang. Prosedur penelitian ini menggunakan metode penelitian tindakan kelas kolaboratif. 


\section{HASIL DAN PEMBAHASAN}

Pada proses pembelajaran ini guru menerapkan model blended learning melalui whatsapp yang terdiri dari lima langkah, yaitu: (1) fase 0 (belajar mandiri di rumah); (2) fase 1 (datang ke kelas untuk belajar); (3) fase 2 (menerapkan kemampuan dalam proyek); dan (4) fase 3 (mengukur pemahaman peserta didik).

Observasi dilaksanakan selama kegiatan pelaksanaan pembelajaran dilakukan. Kegiatan observasi didapatkan beberapa data. Berikut adala data rata-rata hasil observasi pelaksanaan penerapan model blended learning melalui whatsapp terhadap kinerja guru pada siklus I, siklus II, dan siklus III.

Tabel 1. Perbandingan Penerapan Model Blended Learning melalui Whatsapp terhadap

Kinerja Guru Antarsiklus

\begin{tabular}{|c|c|c|c|c|}
\hline \multirow[b]{2}{*}{ No. } & \multirow[b]{2}{*}{ Aspek yang Diamati } & \multicolumn{3}{|c|}{ Skor } \\
\hline & & $\underset{I}{\text { Siklus }}$ & $\underset{\text { SI }}{\text { Siklus }}$ & $\begin{array}{c}\text { Siklus } \\
\text { III }\end{array}$ \\
\hline 1 & Pra-Pembelajaran & 6,5 & 7 & 7,5 \\
\hline 2 & Konstruktivisme & 10 & 11 & 11,5 \\
\hline 3 & Pemodelan & 4 & 4 & 4,5 \\
\hline 4 & $\begin{array}{l}\text { Diskusi Kelompok-Inkuiri Terbimbing- } \\
\text { Bertanya }\end{array}$ & 12,5 & 14,5 & 15 \\
\hline 5 & Penilaian Autentik & 7 & 7,5 & 8 \\
\hline 6 & Refleksi & 7,5 & 8 & 8,5 \\
\hline 7 & $\begin{array}{l}\text { Keterbukaan terhadap Respon Peserta } \\
\text { Didik }\end{array}$ & 7 & 7 & 7 \\
\hline & Skor & 86 & 92 & 96 \\
\hline & Keterangan & SB & SB & SB \\
\hline
\end{tabular}

Berdasarkan tabel 1, dijelaskan terjadi peningkatan kinerja guru terhadap penerapan model blended learning melalui whatsapp. Siklus I kinerja guru sebesar 86, siklus II terjadi peningkatan pada kinerja guru menjadi 92, dan siklus III juga terjadi peningkatan menjadi 96. Hasil tersebut dapat disimpulkan bahwa sintaks model pembelajaran blended learning yang dilaksanakan oleh guru sudah diterapkan dengan sangat baik dan sesuai dengan rencana pelaksanaan pembelajaran yang telah dipersiapkan.

Berikut merupakan data rata-rata hasil tes evaluasi untuk mengukur pemahaman konsep satuan panjang setelah penerapan model blended learning melalui whatsapp pada siklus I, siklus II, dan siklus III.

Tabel 2. Perbandingan Penerapan Model Blended Learning melalui Whatsapp terhadap Keaktifan Peserta Didik Antarsiklus

\begin{tabular}{ccccc}
\hline \multirow{2}{*}{ No. } & \multirow{2}{*}{ Aspek yang Diamati } & \multicolumn{3}{c}{ Skor } \\
\cline { 3 - 5 } & Siklus I & Siklus II & Siklus III \\
\hline 1 & Aktivitas Melihat & 2,68 & 3,54 & 3,58 \\
2 & Aktivitas Lisan & 2,95 & 3,5 & 3,55 \\
3 & Aktivitas Mendengarkan & 3,00 & 3,47 & 3,54 \\
4 & Aktivitas Menulis & 2,86 & 3,58 & 3,63 \\
5 & Aktivitas Mental & 2,77 & 3,48 & 3,52 \\
6 & Aktivitas Emosional & 2,70 & 3,45 & 3,55 \\
\hline & Rata-rata & $2,83(\mathrm{~B})$ & $3,5(\mathrm{SB})$ & $3,56(\mathrm{SB})$ \\
\hline
\end{tabular}

Berdasarkan tabel 2, dijelaskan bahwa terjadi peningkatan keaktifan peserta didik setelah penerapan model blended learning melalui whatsapp. Siklus I rata-rata 
mencapai 2,83 dengan kategori baik, siklus II mengalami peningkatan menjadi 3,5 dengan kategori sangat baik, dan siklus III juga mengalami peningkatan menjadi 3,56 dengan kategori sangat baik. Dari hasil observasi tersebut menunjukkan bahwa aktivitas peserta didik menjadi lebih aktif seperti aktivitas melihat, aktivitas lisan, aktivitas mendengarkan, aktivitas menulis, aktivitas mental, dan ektivitas emosional. Berdasarkan data tersebut membuktikkan bahwa penerapan model pembelajaran blended learning melalui whatsapp dapat meningkatkan keaktifan peserta didik.

Data hasil nilai pemahaman konsep satuan panjang peserta didik kelas II disajikan dalam bentuk tabel perbandingan antarsiklus seperti berikut ini:

Tabel 3. Perbandingan Hasil Nilai Pemahaman Konsep Satuan Panjang Antarsiklus

\begin{tabular}{llcccc}
\hline No. & \multicolumn{1}{c}{ Keterangan } & Pratindakan & $\begin{array}{c}\text { Siklus } \\
\text { I }\end{array}$ & $\begin{array}{c}\text { Siklus } \\
\text { II }\end{array}$ & $\begin{array}{c}\text { Siklus } \\
\text { III }\end{array}$ \\
\hline 1 & Nilai rata-rata kelas & 59 & 64 & 71 & 82 \\
2 & Ketuntasan klasikal & $20 \%$ & $40 \%$ & $54 \%$ & $87 \%$ \\
3 & Nilai tertinggi & 85 & 85 & 85 & 100 \\
4 & Nilai terendah & 30 & 35 & 45 & 65 \\
\hline
\end{tabular}

Berdasarkan tabel 3 menunjukkan bahwa hasil nilai pemahaman konsep satuan panjang peserta didik kelas II SD Negeri 2 Kendalsari Klaten semakin meningkat setelah penerapan model blended learning melalui whatsapp. Hal tersebut ditunjukkan pada presentase jumlah peserta didik yang tuntas $\mathrm{KKM} \geq 78$ pada siklus I peserta didik yang mencapai ketuntasan sebanyak $40 \%$, siklus II mengalami peningkatan menjadi $54 \%$, dan siklus III juga mengalami peningkatan menjadi $87 \%$. Rata-rata kelas juga mengalami peningkatan pada setiap siklus. Siklus I rata-ratanya sebesar 64 , siklus II rata-rata mengalami peningkatan menjadi 71 , dan siklus III mengalami peningkatan menjadi $87 \%$. Nilai tertinggi pada setiap siklus juga mengalami peningkatan. Siklus I nilai tertinggi sebesar 85 , siklus II masih sama sebesar 85 , dan siklus III mengalami peningkatan menjadi 100 .

Berdasarkan uraian tersebut dapat disimpulkan bahwa terdapat peningkatan pemahaman konsep satuan panjang peserta didik dengan menerapkan model pembelajaran blended learning melalui whatsapp pada peserta didik kelas II SD Negeri 2 Kendalsari Klaten Tahun Pelajaran 2020/2021. Hal tersebut relevan atau sesuai dengan penelitian yang telah dilakukan sebelumnya. Penelitian yang dilakukan oleh Masitoh, Yuliyanti, \& Lestari (2018) yang berjudul "Model Pembelajaran berbasis Blended Learning melalui Media Whatsapp dalam Menumbuhkan Critical Thinking pada Siswa SD". Hasil penelitiannya menunjukkan adanya peningkatan terhadap pelaksanaan pembelajaran meliputi kinerja guru, aktivitas peserta didik, dan yang paling utama adalah peningkatan terhadap critical thinking peserta didik pada pembelajaran tematik. Penelitian Suhartono yang menunjukkan penggunaan model blended learning melalui whatsapp dapat diterapakan di sekolah dasar. Menurut Suhartono (2017) pembelajaran blended learning guru dapat memanfaatkan WA sebagai media belajar dimana guru dapat memasukkan tugas-tugas, diskusi, dan tes untuk dikerjakan peserta didik di rumah dengan bimbingan orang tua.

Peningkatan pemahaman konsep satuan panjang peserta didik setelah penerapan model blended learning melalui whatsapp dikarenakan beberapa penyebab, yaitu: (1) Guru selalu memahami rencana pelaksanaan pembelajaran sehingga dapat memaksimalkan waktu yang ada ketika pembelajaran dilaksanakan di kelas; (2) Guru pasti mengawahkan peserta didik untuk selalu aktif bertanya terhadap materi yang belum dipahami; (3) Guru mengarahkan peserta didik untuk aktif ketika berdiskusi pada masing-masing kelompok; (4) Peserta didik selalu menyajikan analisis pada lembar kerja sehingga dapat mencapai tingkatan kognitif yang lebih tinggi; dan (5) 
Guru melakukan inovasi dan variasi dalam menyampaikan materi pembelajaran seperti melalui Google Site atau YouTube.

Namun dalam pelaksanaan model pembelajaran blended learning melalui whatsapp terdapat beberapa kendala terutama hal teknis, yaitu: (1) Kuota internet yang cepat habis; (2) Sinyal internet yang kurang memadai; (3) Kurangnya perhatian orang tua ketika belajar mandiri; dan (4) Rendahnya kesadaran pentingnya literasi digital dan teknologi pada zaman sekarang. Sedangkan solusi yang diberikan oleh pihak guru dan sekolah adalah sebagai berikut: (1) Pihak sekolah emmberikan bantuan kuota internet; (2) Guru meminta bantuan kepada pihak balai desa untuk membagikan WiFi agar peserta didik dapat belajar secara mandiri; (3) Guru selalu memberikan motivasi kepada orang tua dan peserta didik agar selalu bertanya jika merasa kesulitan; dan (4) Guru menjelaskan pentingnya literasi digital dan teknologi terutama pada zaman sekarang yang sedang masa pandemi covid-19.

Berdasarkan data hasil penelitian dan pembahasan lalu dikaitkan dengan teori dan penelitian yang relevan maka dapat disimpulkan bahwa penerapan model blended learning melalui whatsapp terbukti dapat meningkatkan pemahaman konsep satuan panjang peserta didik kelas II SD Negeri 2 Kendalsari Klaten Tahun Pelajaran 2020/2021.

\section{SIMPULAN}

Berdasarkan hasil tindakan, analisis, dan pembahasan yang telah diuraikan dapat disimpulkan bahwa:

1. Penerapan model blended learning melalui whatsapp dapat meningkatkan pemahaman konsep satuan panjang di SDN 2 Kendalsari Klaten. Hal ini dibuktikan dengan pencapaian rata-rata nilai pada siklus I sebesar 64 , siklus II sebesar 71 , dan siklus III sebesar 82 dengan $\mathrm{KKM} \geq 78$.

2. Kendala penerapan model blended learning melalui whatsapp yaitu; (1) Guru masih kesulitan dalam mengintegrasikan muatan-muatan pembelajaran pada pembelajaran tematik; (2) Peserta didik ada yang belum percaya diri menyampaikan pendapat; dan (3) Ada peserta didik yang pasif dalam berdiskusi. Adapun solusinya adalah (1) Guru harus menyiapkan perangkat pembelajaran sebaik mungkin; (2) Guru harus melakukan pendekatan kepada peserta didik dengan tanya jawab; dan

(3) Guru melakukan inovasi dan variasi dalam menyampaikan materi.

Berdasarkan simpulan yang telah diuraikan, perlu disampaikan saran-saran sebagai berikut: (1) bagi peserta didik hendaknya berani bertanya tentang materi; berdiskusi dalam membuat suatu kesimpulan, memberikan alasan dengan uraian yang jelas dan tepat, dan mempelajari terlebih dahulu materi; (2) bagi guru hendaknya melaksanakan pembelajaran sesuai dengan sintaks model blended learning; (3) bagi sekolah hendaknya memberikan sosialisasi kepada guru tentang penerapan model blended learning, dan (4) bagi peneliti lain hendaknya memperhatikan kembali masalah dan mengkaji ulang teori.

\section{DAFTAR PUSTAKA}

Arikunto, S., Suhardjono, \& Supardi. (2017). Penelitian Tindakan Kelas (Suryani (ed.); Revisi). Bandung: Bumi Aksara.

Doherti, E. N. C., \& Wulandari, M. (2020). The Impementation of Flipped Classroom in Promoting Students' Autonomy in a Call Class. Asian EFL Journal, 27(32), 264286. Diakses dari http://jurnalftk.uinsby.ac.id

E., R. J. (2003). Blended Learning Opportunities to Enhance Educational Programming and Meetings. Association Management.

Hermawan. (2015). Penelitian Tindakan Kelas \& Penelitian Tindakan Sekolah (Juknis) 
(Indianto (ed.); 1st ed.). Surakarta: UNS Press.

Hidayat, P. W. (2018). Analisis Profil Minat Belajar Dan Kemampuan Pemahaman Konsep Dasar Matematika SD Pada Mahasiswa S1 PGSD STKIP Muhammadiyah Muara Bungo Puput Wahyu Hidayat. IV(1), 62-74. Diakses dari http://ejournal.stkip-pgri-sumbar.ac.id

Husamah. (2014). Pembelajaran Bauran (Blended Learning). Malang: Prestasi Pustaka Jaya.

Rizkiyah, A. (2018). Penerapan Blended Learning untuk Meningkatkan Hasil Belajar Siswa pada Mata Pelajaran IImu Bangunan di Kelas X TGB SMK Negeri 7 Surabaya. Jurnal Kajian Pendidikan Teknik Bangunan, 1(1), 40-49. Diakses dari http://jurnalmahasiswa.unesa.ac.id

Roshonah, A. F., Sutihat, \& Alam, A. (2020). Penerapan Model Blended Learning untuk Meningkatkan Prestasi Belajar Matematika di SDN Pisangan 01. 1-10. Diakses dari http://jurnal.umj.ac.id

Sellawati Nurul Masitoh, Ikrima Dwi Yuliyanti, Uci Dia Ayu Lestari, C. Z. F. (2018). Model Pembelajaran Berbasis Blended Learning Melalui Media Whatsapp dalam Menumbuhkan Critical Thingking pada Siswa SD. Prosiding FKIP Universitas Jember, 115-120. Diakses dari http://jurnal.unej.ac.id

Suhartono. (2017). Menggagas Penerapan Pendekatan Blended Learning Di Sekolah Dasar. Jurnal Kreatif, 177-188. Diakses dari http://journal.unnes.ac.id

Wicaksono, A. (2015). Penerapan Model Pembelajaran Flipped Classroom dengan Pendekatan Project Based Learning Untuk Mata Pelajaran Biologi Kelas $X$ studikasus: SMA N 1. April. Diakses dari http://repository.uksw.edu 